\title{
Blood Trace Element Status in Multiple Sclerosis: a Systematic Review and Meta-analysis
}

\author{
Elahe Nirooei ${ }^{1}$. Seyyed Mohammad Amin Kashani ${ }^{1}$. Soroor Owrangi ${ }^{1} \cdot$ Fatemeh Malekpour $^{2} \cdot$ Maryam Niknam $^{3}$. \\ Fatemeh Moazzen ${ }^{4}$. Peyman Nowrouzi-Sohrabi ${ }^{1,3}$. Somaye Farzinmehr ${ }^{5} \cdot$ Hamed Akbari $^{6}$
}

Received: 11 November 2020 / Accepted: 31 January 2021

(C) The Author(s), under exclusive licence to Springer Science+Business Media, LLC part of Springer Nature 2021

\begin{abstract}
The aim of this meta-analysis was to investigate whether the blood concentrations of patients with multiple sclerosis (MS) are associated with those of the healthy control group in terms of trace elements including zinc ( $\mathrm{Zn})$, iron (Fe), manganese (Mn), magnesium $(\mathrm{Mg})$, selenium $(\mathrm{Se})$, and copper $(\mathrm{Cu})$. A comprehensive search was performed in online databases including PubMed, Scopus, Embase, and Web of Science for studies, which have addressed trace elements in MS up to July $23,2020$. The chi-square test and $I^{2}$ statistic were utilized to evaluate inter-study heterogeneity across the included studies. Weighted mean differences (WMDs) and corresponding 95\% CI were considered as a pooled effect size (ES). Twenty-seven articles (or 32 studies) with a total sample comprised of 2895 participants (MS patients $(n=1567)$ and controls $(n=1328))$ were included. Pooled results using random-effects model indicated that the levels of $\mathrm{Zn}$ (WMD $=-7.83 \mathrm{mcg} / \mathrm{dl}, 95 \% \mathrm{CI}=-12.78$ to $-2.87, \mathrm{Z}$ $=3.09, P=0.002)$, and Fe (WMD $=-13.66 \mathrm{mcg} / \mathrm{dl}, 95 \% \mathrm{CI}=-23.13$ to $-4.19, \mathrm{Z}=2.83, P=0.005)$ were significantly lower in MS patients than in controls. However, it was found that levels of $\mathrm{Mn}(\mathrm{WMD}=0.03 \mathrm{mcg} / \mathrm{dl}, 95 \% \mathrm{CI}=0.01$ to $0.04, Z=2.89, P=$ 0.004 ) were significantly higher in MS patients. Yet, no significant differences were observed in the levels of $\mathrm{Mg}, \mathrm{Se}, \mathrm{and} \mathrm{Cu}$ between both groups. This meta-analysis revealed that the circulating levels of $\mathrm{Zn}$ and Fe were significantly lower in MS patients and that Mn level was significantly higher than those in the control group. However, it was found that there was no significant difference between MS patients and controls with regard to levels of $\mathrm{Mg}, \mathrm{Se}$, and $\mathrm{Cu}$.
\end{abstract}

Keywords Trace element $\cdot$ Multiple sclerosis $\cdot$ Meta-analysis $\cdot$ Zinc $\cdot$ Iron

\section{Introduction}

Multiple sclerosis (MS) is a chronic inflammatory demyelinating disease of the central nervous system (CNS). Moreover,

Somaye Farzinmehr

farzinmehrsomaye@gmail.com

1 Student Research Committee, Shiraz University of Medical Sciences, Shiraz, Iran

2 Family Medicine Department, Shiraz University of Medical Sciences, Shiraz, Iran

3 Department of Biochemistry, School of Medicine, Shiraz University of Medical Sciences, Shiraz, Iran

4 Department of Hematology, Faculty of Allied Medicine, Bushehr University of Medical Sciences, Bushehr, Iran

5 Clinical Neurology Research Center, Shiraz University of Medical Sciences, Shiraz, Iran

6 Department of Biochemistry, School of Medicine, Kerman University of Medical Sciences, Kerman, Iran it is considered the most common cause of neurological disability in young individuals [42]. This neurological $\mathrm{T}$ cellmediated autoimmune disease is characterized by inflammation, reactive astrogliosis, oligodendrocyte depletion, and demyelination in the brain, spinal cord, and optic nerve [41, 63]. Given that MS affects over 2.5 million people around the world, the disease has turned into an urgent issue in healthcare [13]. MS has three clinical subtypes which include relapsingremitting MS (RR-MS), primary progressive MS (PPMS), and secondary progressive MS (SPMS) [19]. Despite the still unknown etiology of the disease, it is clear that the interaction between several immunologic, environmental, infectious, and genetic factors account for the pathogenesis of MS [9].

Trace metals are involved in different MS-related pathophysiological mechanisms [39]. Not only are they essential for the synthesis and stability of myelin but they are also required for CNS to function normally [47]. As a trace element which abounds in the human brain, zinc $(\mathrm{Zn})$ comprises a group of several major myelin proteins including myelin basic protein (MBP) with important functional roles in myelin homeostasis, 
regulation of the immune system, and neuronal and oligodendrocyte death, hence its extensive role in MS pathogenesis [3, 8, 9]. Iron $(\mathrm{Fe})$ is critical for normal neuronal metabolisms like mitochondrial energy generation and myelination [30, 31]. However, the excessive iron levels in the brain may cause iron-induced oxidative stress, thereby contributing to the neurodegeneration seen in MS [65]. Manganese (Mn) is an essential trace element with essential roles in normal growth, as well as in cellular homeostasis and development [17]. Despite its importance, excessive levels of Mn are toxic to the CNS and its implications in MS have been defined [39, 62].

In addition, having a significant effect on the nervous system by decreasing the excitability of nerve cells [29], magnesium $(\mathrm{Mg})$ increases the inhibitory effect and decreases the stimulant effect of autonomic ganglia. Moreover, $\mathrm{Mg}$ ions prevent excessive stimulation via competition with calcium ions on the nerve endings [32]. Mg deficiency induces dysfunction in lymphocytes or nerve cells which is likely to be implicated in the etiology of MS [11]. Likewise, it is believed that oxidative stress plays a crucial role in the demyelination pathogenesis and neurodegeneration in MS [23, 44]. Furthermore, as a potent antioxidant, selenium (Se) is not only likely to have a positive effect on MS but also its deficiency may be contributed to cell death and have some effects on MS induction [51]. Likewise, copper $(\mathrm{Cu})$ is involved in myelin synthesis and has a significant role in many neurodegenerative diseases [3]. Moreover, it is shown that $\mathrm{Cu}$ plays a role in the structure and function of several brain enzymes, as well as in regulating neurotransmitters synthesis, iron metabolism, and oxidative defense. The oxidative damage caused by excessive copper accounts for the role of copper in MS pathology [27, $52,61]$.

Previous studies evaluated the associations between the homeostasis status of abnormal trace metals and MS, although they obtained conflicting results. The present systematic review and meta-analysis aimed to summarize the available findings regarding the circulating levels of $\mathrm{Zn}, \mathrm{Se}, \mathrm{Cu}, \mathrm{Mg}$, and $\mathrm{Fe}$ in MS patients and healthy controls.

\section{Methods}

The protocol for the review was registered with PROSPERO (Provisional registration number: CRD42020204700). After the search strategy was prepared, the online databases including Web of Science (WOS), PubMed, Embase, and Scopus were searched systematically up until July 23, 2020. The following MeSH (Medical Subject Headings) terms and keywords were used for studies on MS and levels of common trace element: ["Multiple sclerosis (MS)" AND "Trace element" OR "Zinc (Zn)" OR "Iron (Fe)" OR "Manganese (Mn) " OR "Magnesium (Mg)" OR "Selenium (Se)" OR "Copper $(\mathrm{Cu})$ "]. The search strategy was supplemented for the Scopus database with more details (Supplementary File. S1). In addition, additional manual searches were conducted according to the reference lists of previous reviews and eligible studies for further pertinent literature.

\section{Study Selection}

When the screening process was performed based on the titles and abstracts, two independent authors (FM and SMAK) identified the eligible studies according to the inclusion and exclusion criteria. Any discrepancy in the way the studies were selected was resolved through discussion, resulting in a consensus or consultation with a third author (HA).

Studies were selected in our meta-analysis if they (1) had an original observational design (cross-sectional, case-control, or cohort); (2) investigated the associations between the status of trace elements of interest in both MS patients and controls and, moreover, defined the diagnostic criteria for MS and trace element measurement; (3) presented a sufficient amount of data in order to extract or calculate the mean and standard deviation (SD) for levels of at least a single trace element of interest in both MS patients and controls; 4) were written in English. Moreover, the exclusion criteria were animal studies, reviews, case reports, case series, randomized controlled trials, editorials, letters, abstracts without full texts, and studies without controls or any insufficient data. Additionally, studies that measured trace elements only in cerebrospinal fluid (CSF) or in the whole blood, and those conducted without the inclusion of any MS patients were also excluded.

\section{Data Extraction and Quality Assessment}

Standardized data collection sheets were used to extract the following information: first author's name, publication year, the country where the study was conducted, study design, sample size (MS patients/ controls), the main characteristics of subjects, type of MS, the way the blood samples were collected, measurement method for trace elements, and the mean and SD levels of trace elements including $\mathrm{Zn}, \mathrm{Fe}, \mathrm{Mn}$, $\mathrm{Mg}, \mathrm{Se}$, and $\mathrm{Cu}$ in both MS patients and controls. Two authors (FM and $\mathrm{SO}$ ) independently extracted data from the qualified studies, which were then checked by a third author (EN) in terms of data extraction accuracy. If an included study did not directly report the SD in both groups, the equation listed in the Cochrane handbook was used to calculate the SD from standard error of the mean (SEM), interquartile, or range for each eligible study.

The Newcastle-Ottawa Scale (NOS) was applied to determine the risk of bias in the included studies. The three points used for the purpose of critical appraisal included the selection of subjects, comparability of included groups, and outcome/ exposure ascertainment. The NOS scores ranged from 0 to 9 . Depending on the type of study, quality scores $\geq 7$ in case- 
control or cohort designs and $\geq 5$ in cross-sectional designs were considered as good quality (Table 1 and Supplementary Table S1).

\section{Statistical Analysis}

All of the statistical analyses were conducted using the software STATA 11.0 (STATA Corp, College Station, Texas). The mean and SD of trace elements in both groups (MS patients/controls) were used to pool the data. All measurements of trace elements were converted to an equal unit ( $\mathrm{mcg} / \mathrm{dl})$. Moreover, we considered weighted mean differences (WMDs) and the corresponding 95\% CI as a pooled effect size (ES). The chi-square test and $I^{2}$ statistic were utilized to evaluate inter-study heterogeneity across the included studies. Likewise, in the presence of significant heterogeneity (with a $P \leq 0.1$ for chi-square result with $I^{2}$ value $\geq$ $50 \%$ ), a random-effects model, otherwise, a fixed-effect model was used to combine ESs. Additional methods including subgroup analyses (based on study design, region, type of MS, and blood sampling) and sensitivity analyses were also performed to identify the source of inter-study heterogeneity. Moreover, univariate meta-regression analyses were conducted to assess if the factors including publication year, total sample size, and quality scores were associated with pooled ESs. The quantitative statistics including Egger's linear regression test and Begg's rank correlation test were used to evaluate the potential evidence of publication bias across the included studies in the current meta-analysis.

\section{Results}

\section{Literature Search and Study Characteristics}

The PRISMA flow diagram for identification and selection of studies in the present systematic review and meta-analysis are shown in Fig. 1. The initial online search in the literature led to the identification of 10,490 records (includes 893 from PubMed, 3721 from Web of Science, 3579 from Scopus, and 2297 from Embase). Upon the removal of duplicate records, the titles and abstracts for 7459 records were screened, leading to the exclusion of 6497 studies. Based on the exclusion criteria (as mentioned before), 962 full-text articles were assessed for eligibility and 935 articles were excluded. Finally, 27 articles (32 studies) were extracted to include in the current metaanalysis $[1,2,4,7,12,14,15,20,22,24,26,28,29,33,34$, $36-38,40,43,45,49,53,55,57-59,62]$. It is, moreover, noteworthy that all 32 studies included 2895 participants (1567 MS patients and 1328 control group participants).

These studies were conducted mainly in Europe and published between 1980 and 2020. The included studies reported the trace element levels of serum or plasma. Additionally, the main characteristics of the qualified studies are displayed in Table 1.

\section{Main Outcomes}

Figure 2 depicts the forest plots for the pooled estimates of the weighted mean differences on trace elements between MS patients and control groups.

\section{Zn Among MS Patients and Controls}

The results obtained from the meta-analysis, based on 17 qualified studies using a random-effects model, indicated that $\mathrm{Zn}$ levels were considerably lower in MS patients than in those of the controls $(\mathrm{WMD}=-7.83 \mathrm{mcg} / \mathrm{dl}, 95 \% \mathrm{CI}=-12.78$ to $2.87)$, along with considerable inter-heterogeneity $\left(I^{2}=\right.$ $99.0 \%, P<0.001)$. The findings obtained from the subgroup analyses demonstrated that the heterogeneity decreased within some of subgroups. As observed in Table 2, the pooled effect size did not significantly change in different study designs. However, it was reported that $\mathrm{Zn}$ levels decreased in studies conducted among MS patients in Europe $(n=7, \mathrm{WMD}=-$ $11.09 \mathrm{mcg} / \mathrm{dl}, 95 \% \mathrm{CI}=-15.85$ to $-6.34 ; I^{2}=79.9 \%, P<$ $0.001)$, America $(n=5, \mathrm{WMD}=-5.34 \mathrm{mcg} / \mathrm{dl}, 95 \% \mathrm{CI}=-$ 10.08 to $\left.-0.60 ; I^{2}=98.5 \%, P<0.001\right)$, and Africa $(n=2$, $\mathrm{WMD}=-15.44 \mathrm{mcg} / \mathrm{dl}, 95 \% \mathrm{CI}=-22.97$ to $-7.91 ; I^{2}=$ $0.0 \%, P=0.728$ ). A stratification of studies based on the type of MS revealed significant decreases in Zn Levels among patients with other types of MS $(n=3, \mathrm{WMD}=-14.91$ $\mathrm{mcg} / \mathrm{dl}, 95 \% \mathrm{CI}=-18.03$ to $-11.79 ; I^{2}=0.0 \%, P=$ $0.931)$. Serum $\mathrm{Zn}$ reduced significantly among MS patients compared with other blood sampling methods $(n=13$, WMD $=-10.52 \mathrm{mcg} / \mathrm{dl}, 95 \% \mathrm{CI}=-20.26$ to $-0.78 ; I^{2}=99.2 \%, P<$ 0.001 ). In addition, the meta-regression analysis indicated that the total sample size across the included studies was negatively related to the decreased zinc levels in MS patients $(\beta=-$ $0.11, P=0.026$ ) (Table 3). The results of sensitivity analysis also showed that the pooled WMD for Zn levels was stable after the studies were excluded one by one (Supplementary Fig. S1). Moreover, no potential evidence of publication bias was observed across the qualified studies ( $P=0.172$ for Egger's test and $P=0.410$ for Begg's test).

\section{Fe Among MS Patients and Controls}

The pooled effect size from 12 qualified studies using a random-effects model indicated that Fe levels in MS patients were lower compared with those in the controls (WMD = $13.66 \mathrm{mcg} / \mathrm{dl}, 95 \% \mathrm{CI}=-23.13$ to -4.19$)$. Their $P$ and $I^{2}$ for heterogeneity tests were statistically significant $\left(I^{2}=92.3 \%, P\right.$ $<0.001)$. The findings of subgroup analyses showed that the heterogeneity decreased within some of the subgroups. As shown in Table 2, in comparison with other regions, Fe levels decreased in studies conducted among MS patients in Asia ( $n$ $=3, \mathrm{WMD}=-9.98 \mathrm{mcg} / \mathrm{dl}, 95 \% \mathrm{CI}=-18.12$ to $-1.84 ; I^{2}=$ $24.8 \%, P=0.265)$. In addition, the subgroup analysis based 


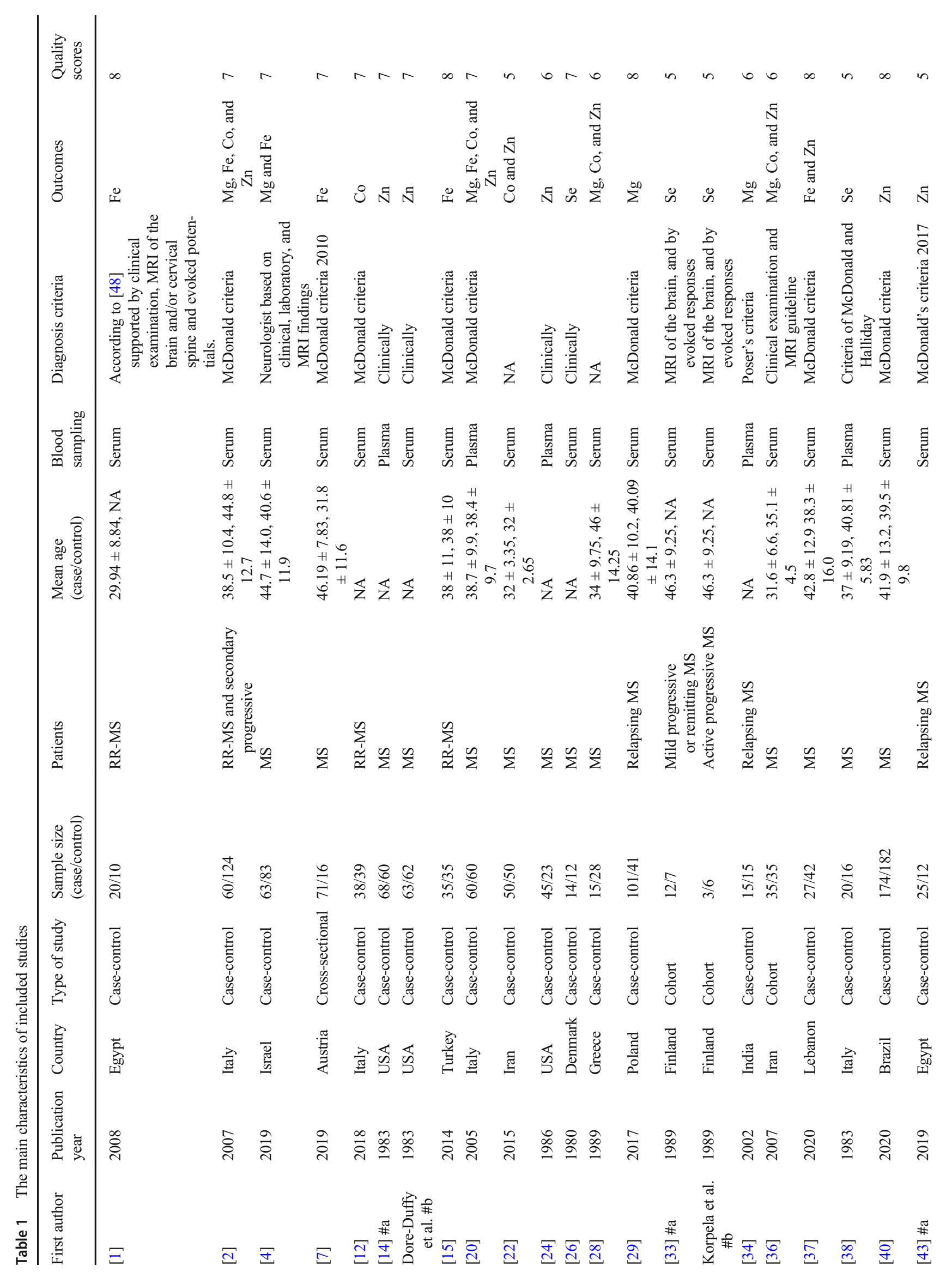




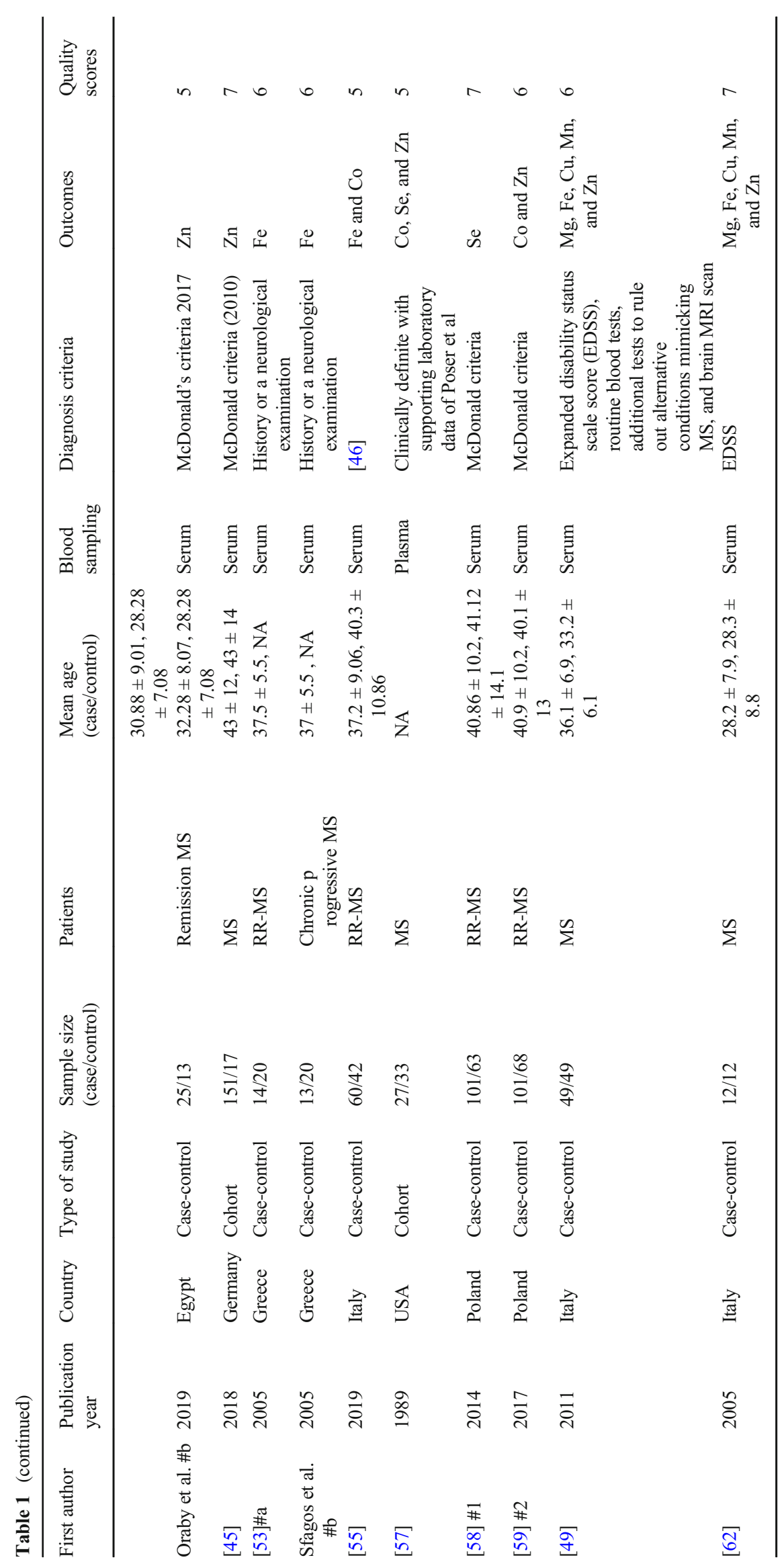



identification and selection process
Fig. 1 Flow chart of the studies

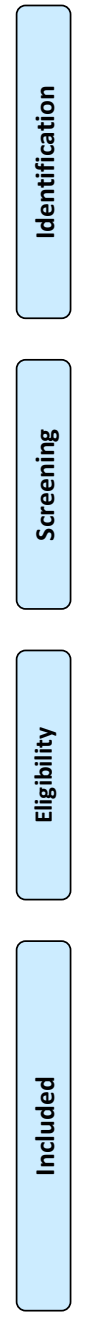

on the type of MS indicated significantly decreased levels of $\mathrm{Fe}$ in patients with no specific $\mathrm{MS}(n=6, \mathrm{WMD}=-23.61$ $\mathrm{mcg} / \mathrm{dl}, 95 \% \mathrm{CI}=-42.42$ to $\left.-4.79 ; I^{2}=90.8 \%, P=0.016\right)$. Furthermore, Fe levels were shown to be lower in studies with case-control designs $(n=11, \mathrm{WMD}=-13.21 \mathrm{mcg} / \mathrm{dl}, 95 \% \mathrm{CI}$ $=-23.00$ to $\left.-3.43 ; I^{2}=92.9 \%, P<0.001\right)$ and in those with serum blood sampling $(n=11, \mathrm{WMD}=-14.77 \mathrm{mcg} / \mathrm{dl}, 95 \%$ $\mathrm{CI}=-29.45$ to $\left.-0.08 ; I^{2}=92.9 \%, P<0.001\right)$. The results obtained from the meta-regression analyses revealed that the studied continuous factors did not have any statistically significant effects on Fe concentrations (Table 3). Moreover, the pooled findings for Fe remained constant in sensitivity analysis (Supplementary Fig. S5). Begg's test $(P=0.583)$ and Egger's test $(P=0.277)$ also were estimated to have no significant evidence of publication bias.

\section{Mn Among MS Patients and Controls}

In accordance with four qualified studies which were pooled, by using a random-effects model, meta-analysis results indicated that Mn levels were higher in MS patients than in

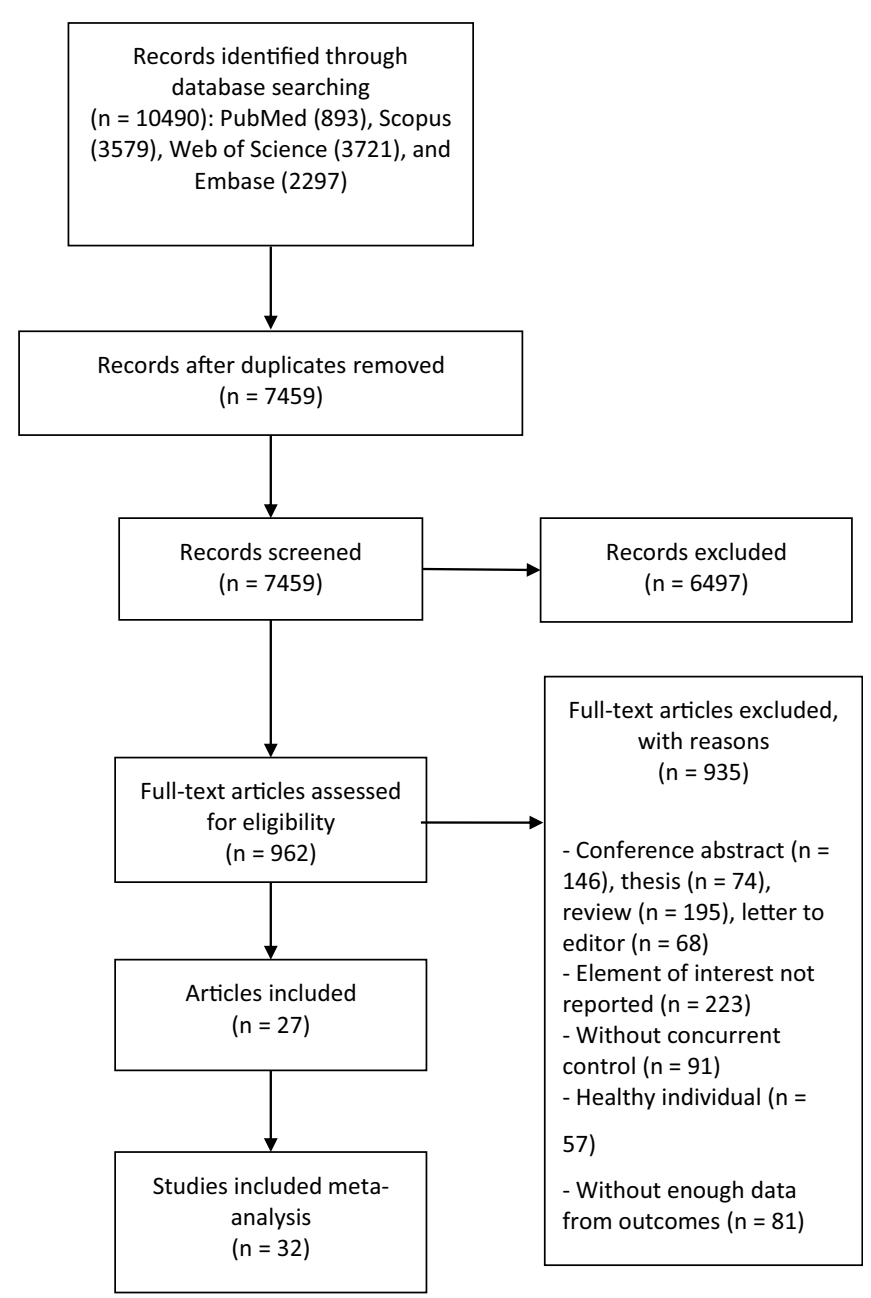

controls $(\mathrm{WMD}=0.03 \mathrm{mcg} / \mathrm{dl}, 95 \% \mathrm{CI}=0.01$ to 0.04$)$, along with considerable inter-heterogeneity $\left(I^{2}=81.5 \%, P=0.001\right)$. As the number of included studies for this outcome was few, additional analyses could not be conducted to assess the source of inter-study heterogeneity. However, the included studies for Mn were from Europe with a case-control design. Likewise, the sensitivity analysis indicated that the exclusion of the study by Ristori et al. [49] changed the pooled effect size $(\mathrm{WMD}=0.03,95 \% \mathrm{CI}-0.00,0.07)$. Moreover, it should be noted that no potential evidence of publication bias was found across the included studies ( $P=0.174$ for Begg's test and $P=0.449$ for Egger's test).

\section{Mg Among MS Patients and Controls}

Nine studies involving 857 subjects have reported Mg levels. The finding of the meta-analysis conducted using a randomeffects model showed that Mg levels in MS patients were not significantly different from those in control groups (WMD =$182.91 \mathrm{mcg} / \mathrm{dl}, 95 \% \mathrm{CI}=-419.81$ to 53.99$)$. It is noteworthy that additional analyses were conducted, along with the 
Fig. 2 The forest plots of pooled estimates of the weighted mean differences on $\mathrm{Zn}(\mathrm{a}), \mathrm{Se}(\mathrm{b}), \mathrm{Mg}$ (c), $\mathrm{Cu}(\mathrm{d}), \mathrm{Fe}(\mathrm{e}), \mathrm{Mn}(\mathrm{f})$ between MS patients and control groups a ID WMD (95\% CI) Country

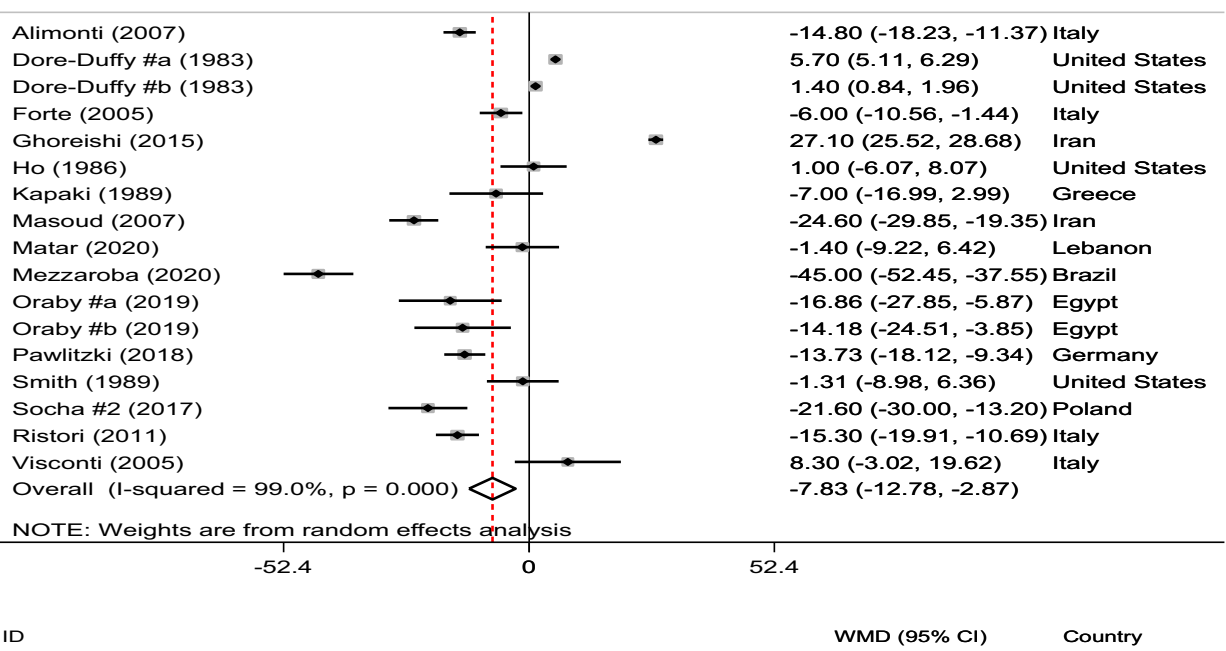

. Jensen (1980)

Korpela \#a (1989)

Korpela \#b (1989)

Mazella (1983)

Smith (1989)

Socha \#1 (2014)

$-1.20(-2.15,-0.25)$

Denmark

$.30(-1.34,1.94)$

Finland

$0.50(-1.50,2.50)$

Finland

$2.58(1.47,3.69)$

Italy

$-0.55(-1.34,0.24)$

United States

Overall (I-squared $=92.5 \%, p=0.000$ )

$-2.40(-3.00,-1.80)$

Poland

$-0.19(-1.69,1.31)$

NOTE: Weights are from random effects analysis

$-3.69$

3.69

C

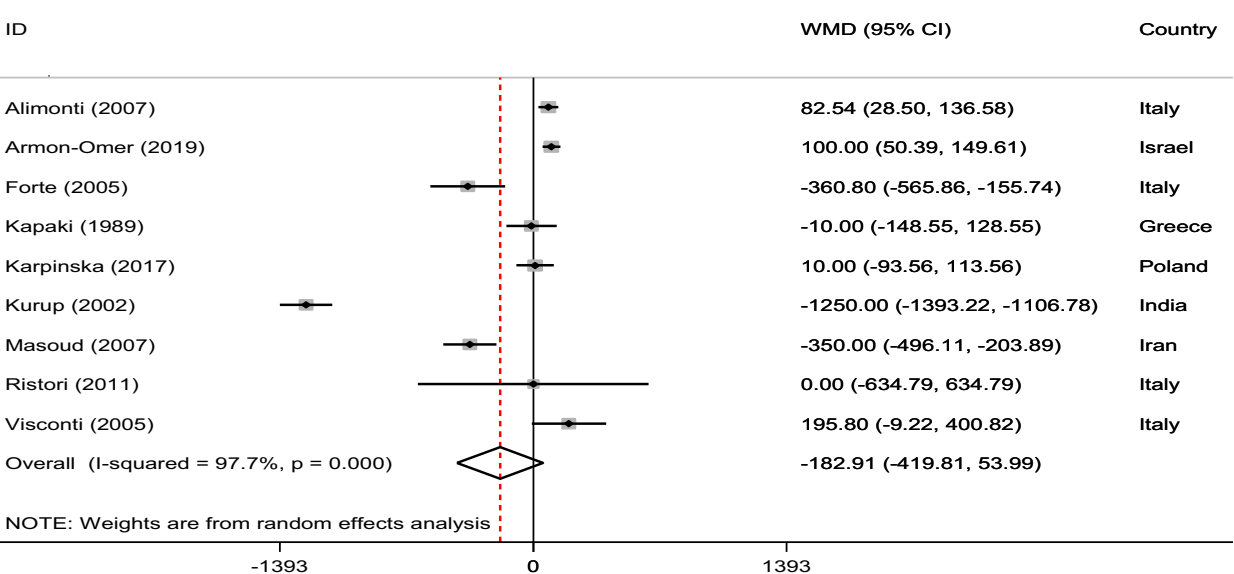

reported heterogeneity across the included studies $\left(I^{2}=\right.$ $97.7 \%, P<0.001)$. With regard to the subgroup analyses and meta-regression, no significant associations were found between the levels of Mg and MS disease (Tables 2 and 3).

Based on the results of sensitivity analysis of the pooled WMD for Mg levels, we did not find any material change after the studies were excluded one by one (Supplementary Fig. S3). Likewise, no potential evidence of publication bias was found across the included studies $(P=0.204$ for Begg's test and $P=0.144$ for Egger's test).

\section{Se Among MS Patients and Controls}

The pooled WMD of eight qualified studies showed that Se concentrations among patients with MS were not significantly different from those of the control group (WMD $=-0.19$ $\mathrm{mcg} / \mathrm{dl}, 95 \% \mathrm{CI}=-1.69$ to 1.31 ). The results also revealed considerable heterogeneity across the included studies $\left(I^{2}=\right.$ $92.5 \%, P<0.001)$. The subgroups' findings indicated that none of the stratified subgroups was associated with Se concentrations (Table 2). However, the inter-heterogeneity is 


\section{d}

\begin{tabular}{|c|c|c|}
\hline ID & WMD $(95 \% \mathrm{Cl})$ & Country \\
\hline Alimonti (2007) & $-1.40(-6.77,3.97)$ & Italy \\
\hline De Riccardis (2018) & $22.55(19.94,25.16)$ & Italy \\
\hline Forte (2005) & $52.40(39.70,65.10)$ & Italy \\
\hline Ghoreishi (2015) & $85.10(82.50,87.70)$ & Iran \\
\hline Kapaki (1989) & $-16.00(-25.19,-6.81)$ & Greece \\
\hline Masoud (2007) & $-23.10(-30.94,-15.26)$ & Iran \\
\hline Siotto (2019) & $5.73(4.94,6.52)$ & Italy \\
\hline Smith (1989) & $0.00(-19.53,19.53)$ & United States \\
\hline Socha \#2 (2017) & $-6.00(-16.69,4.69)$ & Poland \\
\hline Ristori (2011) & $26.00(18.98,33.02)$ & Italy \\
\hline Visconti (2005) & $8.10(-5.48,21.68)$ & Italy \\
\hline Overall (I-squared $=99.7 \%, p=0.000)$ & $14.06(-7.60,35.71)$ & \\
\hline
\end{tabular}

e ID

WMD $(95 \% \mathrm{Cl}) \quad$ Country

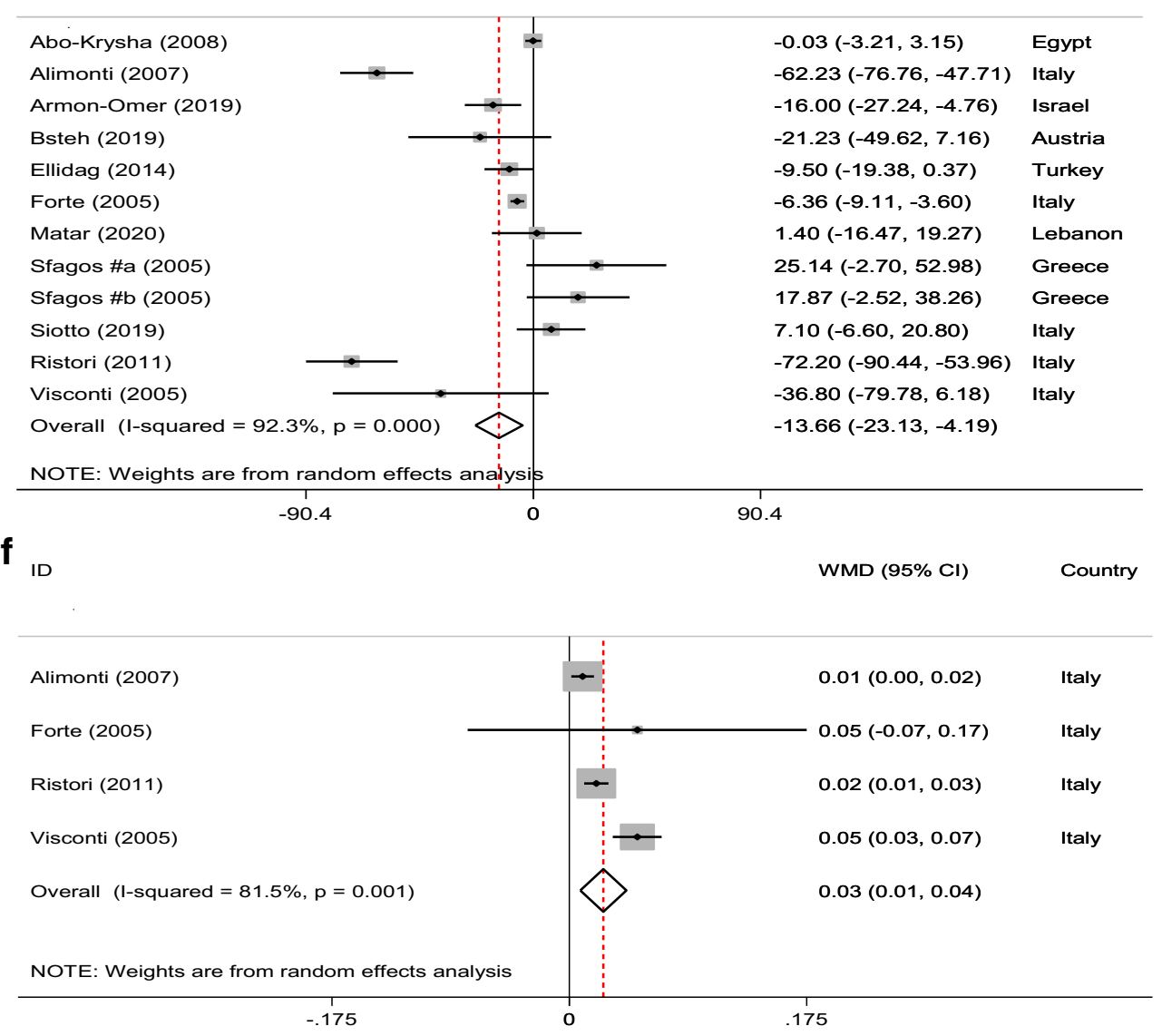

Fig. 2 (continued)

deceased in some strata. Based on the results obtained from meta-regression analyses, the studied continuous factors did not have any statistically significant effects on Se concentrations (Table 3). Moreover, the pooled findings remained constant in sensitivity analyses (Supplementary Fig. S2). The results of Egger's test $(P=0.155)$ and Begg's test $(P=0.188)$ showed that there was no publication bias.

\section{Cu Among MS Patients and Controls}

Eleven studies comprised of $507 \mathrm{MS}$ patients and 540 controls have investigated $\mathrm{Cu}$ levels. According to their pooled results, $\mathrm{Cu}$ concentrations were not significantly different between the two groups (MS patients/controls) $(\mathrm{WMD}=14.06 \mathrm{mcg} / \mathrm{dl}$, $95 \% \mathrm{CI}=-7.60$ to 35.71$)$. However, it was shown that there 
Table 2 Findings of subgroup analyses

\begin{tabular}{|c|c|c|c|c|c|}
\hline \multicolumn{3}{|l|}{ Outcomes } & \multirow{2}{*}{$\begin{array}{l}\text { Number of studies } \\
17\end{array}$} & \multirow{2}{*}{$\frac{\mathrm{WMD}(95 \% \mathrm{CI})}{-7.83(-12.78,-2.87)}$} & \multirow{2}{*}{$\begin{array}{l}I^{2} \text { and } P \text {-value } \\
99.0 \%, P<0.001\end{array}$} \\
\hline $\mathrm{Zn}(\mathrm{mcg} / \mathrm{dl})$ & Total & & & & \\
\hline & Study design & Case-control & 14 & $-6.52(-11.80,-1.25)$ & $99.1 \%, P<0.001$ \\
\hline & & Cohort & 3 & $-13.52(-25.02,-2.01)$ & $92.1 \%, P<0.001$ \\
\hline & & Cross-sectional & - & - & - \\
\hline & Region & Europe & 7 & $-11.09(-15.85,-6.34)$ & $79.9 \%, P<0.001$ \\
\hline & & Asia & 3 & $0.43(-35.87,36.72)$ & $99.5 \%, P<0.001$ \\
\hline & & America & 5 & $-5.34(-10.08,-0.60)$ & $98.5 \%, P<0.001$ \\
\hline & & Africa & 2 & $-15.44(-22.97,-7.91)$ & $0.0 \%, P=0.728$ \\
\hline & Type of MS & Non-specific MS & 13 & $-5.25(-10.67,0.17)$ & $99.1 \%, P<0.001$ \\
\hline & & RR-MS & 1 & $-21.60(-30.00,-13.20)$ & - \\
\hline & & Other & 3 & $-14.91(-18.03,-11.79)$ & $0.0 \%, P=0.931$ \\
\hline & Blood sampling & Serum & 13 & $-10.52(-20.26,-0.78)$ & $99.2 \%, P<0.001$ \\
\hline & & Plasma & 4 & $0.06(-6.80,6.91)$ & $89.8 \%, P<0.001$ \\
\hline \multirow[t]{13}{*}{$\mathrm{Fe}(\mathrm{mcg} / \mathrm{dl})$} & Total & & 12 & $-13.66(-23.13,-4.19)$ & $92.3 \%, P<0.001$ \\
\hline & Study design & Case-control & 11 & $-13.21(-23.00,-3.43)$ & $92.9 \%, P<0.001$ \\
\hline & & Cohort & - & - & - \\
\hline & & Cross-sectional & 1 & $-21.23(-49.62,7.16)$ & - \\
\hline & Region & Europe & 8 & $-18.48(-40.36,3.41)$ & $94.2 \%, P<0.001$ \\
\hline & & Asia & 3 & $-9.98(-18.12,-1.84)$ & $24.8 \%, P=0.265$ \\
\hline & & America & - & - & - \\
\hline & & Africa & 1 & $-0.03(-3.21,3.15)$ & - \\
\hline & Type of MS & Non-specific MS & 6 & $-23.61(-42.42,-4.79)$ & $90.8 \%, P=0.016$ \\
\hline & & RR-MS & 4 & $0.72(-7.75,9.18)$ & $61.0 \%, P=0.053$ \\
\hline & & Other & 2 & $-22.51(-101.01,55.98)$ & $97.5 \%, P<0.001$ \\
\hline & Blood sampling & Serum & 11 & $-14.77(-29.45,-0.08)$ & $92.9 \%, P<0.001$ \\
\hline & & Plasma & 1 & $-6.36(-9.11,-3.60)$ & - \\
\hline \multirow[t]{13}{*}{$\mathrm{Mg}(\mathrm{mcg} / \mathrm{dl})$} & Total & & 9 & $-182.91(-419.81,53.99)$ & $97.7 \%, P<0.001$ \\
\hline & Study design & Case-control & 8 & $-160.83(-415.13,93.48)$ & $97.9 \%, P<0.001$ \\
\hline & & Cohort & 1 & $-350.00(-496.11,203.89)$ & - \\
\hline & & Cross-sectional & - & - & - \\
\hline & Region & Europe & 6 & $-3.01(-120.07,114.04)$ & $75.0 \%, P=0.001$ \\
\hline & & Asia & 3 & $-498.17(-1305.42,309.08)$ & $99.4 \%, P<0.001$ \\
\hline & & America & - & - & - \\
\hline & & Africa & - & - & - \\
\hline & Type of MS & No specific MS & 6 & $-75.75(-272.78,121.28)$ & $90.1 \%, P<0.001$ \\
\hline & & RR-MS & - & - & - \\
\hline & & Other & 3 & $-382.81(-1051.10,285.47)$ & $99.3 \%, P<0.001$ \\
\hline & Blood sampling & Serum & 7 & $7.70(-91.87,107.27)$ & $83.8 \%, P<0.001$ \\
\hline & & Plasma & 2 & $-808.55(-1679.93,62.83)$ & $97.9 \%, P<0.001$ \\
\hline \multirow[t]{10}{*}{$\mathrm{Se}(\mathrm{mcg} / \mathrm{dl})$} & Total & & 6 & $-0.19(-1.69,1.31)$ & $92.5 \%, P<0.001$ \\
\hline & Study design & Case-control & 3 & $-0.37(-3.12,2.38)$ & $96.7 \%, P<0.001$ \\
\hline & & Cohort & 3 & $-0.29(-0.96,0.38)$ & $0.0 \%, P=0.469$ \\
\hline & & Cross-sectional & - & - & - \\
\hline & Region & Europe & 5 & $-0.09(-2.06,1.88)$ & $93.9 \%, P<0.001$ \\
\hline & & Asia & - & - & - \\
\hline & & America & 1 & $-0.55(-1.34,0.24)$ & - \\
\hline & & Africa & - & - & - \\
\hline & Type of MS & No specific MS & 3 & $0.25(-1.81,2.31)$ & $93.1 \%, P<0.001$ \\
\hline & & RR-MS & 1 & $-2.40(-3.00,-1.80)$ & - \\
\hline
\end{tabular}


Table 2 (continued)

\begin{tabular}{|c|c|c|c|c|c|}
\hline \multicolumn{3}{|l|}{ Outcomes } & \multirow{2}{*}{$\begin{array}{l}\text { Number of studies } \\
2\end{array}$} & \multirow{2}{*}{$\begin{array}{l}\text { WMD }(95 \% \mathrm{CI}) \\
0.38(-0.89,1.65)\end{array}$} & \multirow{2}{*}{$\begin{array}{l}I^{2} \text { and } P \text {-value } \\
0.0 \%, P=0.879\end{array}$} \\
\hline & & Other & & & \\
\hline & Blood sampling & Serum & 4 & $-0.92(-2.26,0.43)$ & $82.0 \%, P<0.001$ \\
\hline & & Plasma & 2 & $0.99(-2.08,4.06)$ & $95.1 \%, P<0.001$ \\
\hline \multirow[t]{13}{*}{$\mathrm{Cu}(\mathrm{mcg} / \mathrm{dl})$} & Total & & 11 & $14.06(-7.60,35.71)$ & $99.7 \%, P<0.001$ \\
\hline & Study design & Case-control & 9 & $19.66(-4.48,43.81)$ & $99.8 \%, P<0.001$ \\
\hline & & Cohort & 2 & $-13.35(-35.71,9.01)$ & $78.4 \%, P=0.031$ \\
\hline & & Cross-sectional & - & - & - \\
\hline & Region & Europe & 8 & $11.09(1.92,20.26)$ & $97.3 \%, P<0.001$ \\
\hline & & Asia & 2 & $31.07(-74.97,137.10)$ & $99.8 \%, P<0.001$ \\
\hline & & America & 1 & $0.00(-19.53,19.53)$ & - \\
\hline & & Africa & & & \\
\hline & Type of MS & No specific MS & 7 & $19.03(-22.60,60.66)$ & $99.5 \%, P<0.001$ \\
\hline & & RR-MS & 3 & $8.21(-5.48,21.90)$ & $98.7 \%, P<0.001$ \\
\hline & & Other & 1 & $-1.40(-6.77,3.97)$ & - \\
\hline & Blood sampling & Serum & 9 & $11.35(-12.63,35.33)$ & $99.8 \%, P<0.001$ \\
\hline & & Plasma & 2 & $26.75(-24.59,78.09)$ & $94.9 \%, P<0.001$ \\
\hline
\end{tabular}

was significant inter-heterogeneity across the included studies $\left(I^{2}=99.7 \%, P<0.001\right)$. Moreover, subgroups' findings on the association between MS disease and $\mathrm{Cu}$ levels remained insignificant in different strata of study testing, type of MS, and blood sampling (Table 2). However, the stratification of studies based on the region wherein they were performed revealed significant increases in $\mathrm{Cu}$ levels among patients in Europe ( $n$ $=8, \mathrm{WMD}=11.09 \mathrm{mcg} / \mathrm{dl}, 95 \% \mathrm{CI}=1.92$ to $20.26 ; I^{2}=$ $97.3 \%, P<0.001)$. In addition, the meta-regression analysis showed that the studied continuous factors had no significant effect on the association between MS and $\mathrm{Cu}$ levels (Table 3).
Yet, the pooled WMD in sensitivity analysis remained constant after each study, which addressed the association between the two groups, was excluded (Supplementary Fig. S4). There was no statistically potential publication bias using Begg's test $(P=0.578)$ and Egger's test $(P=0.938)$.

\section{Discussion}

MS is the most frequent chronic inflammatory demyelinating disease of the CNS. It is characterized by autoimmunity and
Table 3 Findings of metaregression analyses

\begin{tabular}{lllllll}
\hline Outcomes & Continues factors & Coefficient & $95 \%$ CI & $P$-value & tau2 & Adj $R$-squared \\
\hline \multirow{2}{*}{ Zn (mcg/dl) } & Publication year & -0.46 & $-1.03,0.12$ & 0.114 & 219.8 & $10.20 \%$ \\
& Total sample size & -0.11 & $-0.20,-0.01$ & 0.026 & 184 & $24.82 \%$ \\
& Quality scores & -3.90 & $-12.51,4.72$ & 0.350 & 244 & $0.31 \%$ \\
\multirow{2}{*}{$\mathrm{Fe}(\mathrm{mcg} / \mathrm{dl})$} & Publication year & 0.15 & $-3.15,3.45$ & 0.922 & 866 & $-11.16 \%$ \\
& Total sample size & -0.32 & $-0.67,0.02$ & 0.064 & 548.5 & $29.60 \%$ \\
& Quality scores & -1.65 & $-23.52,20.22$ & 0.870 & 870.7 & $-11.75 \%$ \\
$\mathrm{Mg}(\mathrm{mcg} / \mathrm{dl})$ & Publication year & 12.58 & $-32.10,57.27$ & 0.527 & 214753 & $-7.97 \%$ \\
& Total sample size & 3.17 & $-3.29,9.62$ & 0.284 & 189228 & $4.87 \%$ \\
& Quality scores & 295.85 & $-214.84,806.55$ & 0.213 & 174672 & $12.18 \%$ \\
$\mathrm{Se}(\mathrm{mcg} / \mathrm{dl})$ & Publication year & -0.09 & $-0.24,0.07$ & 0.193 & 2.08 & $24.94 \%$ \\
& Total sample size & -0.02 & $-0.05,0.01$ & 0.168 & 1.94 & $30.07 \%$ \\
& Quality scores & -1.27 & $-2.81,0.28$ & 0.085 & 1.39 & $50.32 \%$ \\
$\mathrm{Cu}(\mathrm{mcg} / \mathrm{dl})$ & Publication year & 1.05 & $-1.12,3.21$ & 0.301 & 969 & $2.29 \%$ \\
& Total sample size & 0.07 & $-0.42,0.56$ & 0.760 & 1091 & $-9.98 \%$ \\
& Quality scores & -3.77 & $-32.54,24.99$ & 0.773 & 1089 & $-9.82 \%$ \\
\hline
\end{tabular}


neurodegeneration, leading to irreversible and severe clinical disability $[18,21]$. Among the environmental factors, abnormalities of trace elements have been hypothesized to be involved in the pathogenesis of various neurologic diseases, including MS [2, 49]. This systematic review and metaanalysis aimed to ascertain if the blood concentrations of patients with MS and healthy adults are different in terms of $\mathrm{Zn}$, $\mathrm{Fe}, \mathrm{Mn}, \mathrm{Mg}, \mathrm{Se}$, and $\mathrm{Cu}$. Findings obtained from the present meta-analysis revealed significantly lower circulating levels of $\mathrm{Fe}$ and $\mathrm{Zn}$ among patients with MS in comparison with the healthy controls. However, trace elements of $\mathrm{Cu}$ and Se were not significantly different between MS patients and controls. With respect to $\mathrm{Mg}$, there was no significant difference between the two groups.

Zinc is an essential trace element in the brain and a cofactor of more than 300 enzymes including matrix metalloproteinases (MMPs). It is a component of many proteins such as myelin basic protein. Thus, it plays a significant role in MS pathophysiology $[5,45,60]$. Our findings of considerably lower serum $\mathrm{Zn}$ levels in MS patients compared to controls are in line with some previous studies. A previous metaanalysis reported a significant reduction in overall serum/ plasma $\mathrm{Zn}$ levels in patients with MS compared to the controls [6]. Moreover, in a cohort study, it was revealed that MS diagnosis is associated with lower serum zinc concentrations compared to the controls, but without marked zinc deficiency. This cohort study also declared that lower zinc levels in MS patients could be a result of enhanced upregulation of zincdependent MMPs, with higher levels during the active disease stage. Likewise, this upregulation might explain the reported lower zinc levels in RR-MS patients compared to patients with chronic disease [45]. Subsequent to the subgroup analyses, the observed heterogeneity decreased within some of the subgroups, including European and RR-MS ones. It should be noted that Europeans showed lower Zn levels in MS patients compared to controls, implying the need for further investigations to explore the reason behind $\mathrm{Zn}$ deficiency in patients suffering from MS in this region. Moreover, zinc levels were demonstrated to be significantly lower in RR-MS subgroups compared with other types. It is highly recommended that more cohort and clinical trial studies be conducted to assess $\mathrm{Zn}$ therapy in RR-MS patients, as a more common type of MS.

$\mathrm{Fe}$ is a cofactor of various enzymes for normal brain metabolisms [30, 31]. Abnormal Fe homeostasis may contribute to neurodegeneration which is relevant to the pathology of MS. Findings obtained from the present study are consistent with recent works as they revealed that the MS group had considerably lower Fe values in comparison with healthy controls [4]. Iron is considered a key factor in MS pathogenesis, as it may lead to neuronal damage through triggering oxidative stress [35]. Fe subgroup analyses showed lower heterogeneity within different geographical subgroups. In this regard, Asians showed significantly lower circulating levels of $\mathrm{Fe}$ in comparison with other regions. Therefore, studies that are more comprehensive are needed to clarify the observed iron deficiency in Asian patients with MS.

Mn serves as a cofactor for maintaining the function and regulation of many biochemical and cellular reactions, including multiple enzymes, which are critical for synthesis and metabolism of neurotransmitters and neuronal and glial function $[16,25]$. It is also recognized as a neurotoxicant through the formation of hydroxyl radicals that decreases cellular antioxidants and offers crucial implications for MS [56]. Our meta-analysis results indicated, based on four qualified studies, that Mn levels were significantly higher in MS patients than in controls with high heterogeneity. Therefore, further studies with a larger sample size are required to explain the exact implication of $\mathrm{Mn}$ in patients with MS.

$\mathrm{Mg}$ has a key role in the nervous system by reducing the excitability of nerve cells [32]. Mg activates about 320 enzymes and interacts with other minerals, such as calcium, zinc, and aluminum, affecting the immune system and the content of these elements in the central nervous system [64]. Mg deficiency impairs antioxidant defense through decreased activity of $\mathrm{Cu} / \mathrm{Zn}$ superoxide dismutase and reduced glutathione synthesis. It also increases synthesis or activity of injurious mediators, e.g., tumor necrosis factor (TNF), interleukin 6 (IL6), IL-1, oxygen-free radicals, and endothelin, thereby being possibly implicated in the etiology of MS [29]. With respect to $\mathrm{Mg}$, no significant difference was found between the two groups in the present meta-analysis. In a previous study on RR-MS patients, the average serum level of $\mathrm{Mg}$ was normal, but certain abnormalities were observed, due to a high number of MS patients represented a dysregulated serum Mg. As patients with a deficiency and an excess of serum Mg levels had a worse clinical condition, Mg supplementation should be taken after the concentration of this element in the serum is evaluated [29]. Moreover, more studies with a larger sample size are required to explain the exact role played by $\mathrm{Mg}$ in the pathophysiology of MS.

Se is another important trace element that is well known for its key role in the glutathione peroxidase enzyme and its antiinflammatory effect [3]. Because of its potent antioxidant and anti-inflammatory properties, Se may have a protective effect on the course of MS. Therefore, it is frequently claimed that Se deficiency is a common and important issue in MS [51]. In this study, no statistically significant difference was shown between MS patients and controls in terms of their circulating levels of Se, though MS patients demonstrated a lower $\mathrm{Se}$ level compared to the control group.

$\mathrm{Cu}$ is involved in the structure and function of several brain enzymes, oxidative defense, iron metabolism, regulating neurotransmitters, and myelin synthesis [10]. $\mathrm{Cu}$ is also crucial for the normal development of the nervous system [59]. The role of $\mathrm{Cu}$ in MS pathology is shown to be through its excessive 
concentrations and subsequent oxidative damage. Therefore, $\mathrm{Cu}$ levels should be precisely adjusted for essential enzyme activity and prevention of oxidative stress [54]. Based on the present study, no statistically significant difference was found between MS patients and controls in terms of $\mathrm{Cu}$ trace element. However, given higher $\mathrm{Cu}$ levels in MS patients, the assumption that higher circulating levels of $\mathrm{Cu}$ may contribute to MS development is unclear. A recent meta-analysis also showed a higher concentration of $\mathrm{Cu}$ in MS patients compared to the healthy controls [50]. The differences between the results of these meta-analyses may be due to the method used to determine pooled effect size. These findings confirm the possible function of $\mathrm{Cu}$ in MS etiology and could stimulate future studies with longitudinal designs and larger sample sizes.

It should be noted that this meta-analysis had several limitations that should be taken into account. First, given the high heterogeneity of the selected studies, the obtained results should be interpreted with caution. Next, it is likely that the associations reported in the present meta-analysis are affected by participants' gender, age, and/or expanded disability status scale (EDSS) scores that are not addressed in this meta-analysis. This is because the included articles lacked detailed respective information. Furthermore, most of the included studies of this meta-analysis did not take account of the confounding factors including smoking, alcohol, lifestyle habits, and dietary intake of trace elements. Accordingly, the aforementioned factors are to be addressed in subsequent studies assessing the association between the level of trace elements and MS. A strength of this meta-analysis would be the pooled result of the minerals that permits a precise assessment of the relationship between the circulating levels of the trace elements and MS. To identify the possible sources of heterogeneity in our study, a subgroup analysis was conducted. Likewise, since no publication bias was detected, it is likely that the obtained results are not biased. Notably, iodine (I) was considered as a trace element in our search, although no article was found to report the role of this element in MS.

\section{Conclusion}

This meta-analysis revealed that patients with MS had lower $\mathrm{Zn}$ and $\mathrm{Fe}$ as compared with the controls. Mn levels were significantly higher in MS patients than in the controls. In addition, $\mathrm{Fe}$ and $\mathrm{Zn}$ levels were influenced by the region and disease subtypes. However, it was also shown that MS patients were not significantly associated in terms of Se, $\mathrm{Mg}$, and $\mathrm{Cu}$. It is suggested that additional, larger, and welldesigned clinical studies, especially on iodine and other trace elements with lower available evidence, could produce invaluable results in the context of MS. Given the substantial heterogeneity among the included studies, the results should be treated with caution. Finally, the identification of potential nutritional supplements such as trace elements may provide valuable insights into the treatment options for MS, especially for patients in whom disease-modifying drugs do not prevent disease progression or nutritional deficiencies are prevalent.

Supplementary Information The online version contains supplementary material available at https://doi.org/10.1007/s12011-021-02621-5.

Author Contributions All named authors meet the International Committee of Medical Journal Editors (ICMJE) criteria for authorship for this article, take responsibility for the integrity of the work as a whole, and have given their approval for this version to be published.

Data Availability Data will be made available on reasonable request.

\section{Declarations}

Ethics Approval and Consent to Participate This article is based on previously conducted studies and does not contain any studies with human participants or animals performed by any of the authors.

Conflict of Interest The authors declare no conflict of interest.

\section{References}

1. Abo-Krysha N, Rashed L (2008) The role of iron dysregulation in the pathogenesis of multiple sclerosis: an Egyptian study. (Accessed 5 14)

2. Alimonti A, Ristori G, Giubilei F, Stazi MA, Pino A, Visconti A, Brescianini S, Monti MS, Forte G, Stanzione P (2007) Serum chemical elements and oxidative status in Alzheimer's disease, Parkinson disease and multiple sclerosis. Neurotoxicology 28(3): 450-456

3. Alizadeh A, Mehrpour O, Nikkhah K, Bayat G, Espandani M, Golzari A, Jarahi L, Foroughipour M (2016) Comparison of serum concentration of $\mathrm{Se}, \mathrm{Pb}, \mathrm{Mg}, \mathrm{Cu}, \mathrm{Zn}$, between MS patients and healthy controls. Electron Physician 8(8):2759-2764

4. Armon-Omer A, Waldman C, Simaan N, Neuman H, Tamir S, Shahien R (2019) New insights on the nutrition status and antioxidant capacity in Multiple Sclerosis patients. Nutrients 11(2):427

5. Berlet HH, Bischoff H, Weinhardt F (1994) Divalent metals of myelin and their differential binding by myelin basic protein of bovine central nervous system. Neurosci Lett 179(1-2):75-78

6. Bredholt M, Frederiksen JL (2016) Zinc in multiple sclerosis: a systematic review and meta-analysis. ASN Neuro 8(3): 1759091416651511

7. Bsteh G, Haschka D, Tymoszuk P, Berek K, Petzer V, Hegen H, Wurth S, Auer M, Zinganell A, Pauli FD, Deisenhammer F, Weiss G, Berger T (2019) Serum hepcidin levels in multiple sclerosis. Mult Scler J 5(4):2055217319885984

8. Choi BY, Jang BG, Kim JH, Seo J-N, Wu G, Sohn M, Chung TN, Suh SW (2013) Copper/zinc chelation by clioquinol reduces spinal cord white matter damage and behavioral deficits in a murine MOG-induced multiple sclerosis model. Neurobiol Dis 54:382391

9. Choi BY, Jung JW, Suh SW (2017) The emerging role of zinc in the pathogenesis of multiple sclerosis. Int J Mol Sci 18(10):2070

10. Crichton RR, Dexter D, Ward RJ (2008) Metal based neurodegenerative diseases - from molecular mechanisms to therapeutic strategies. Coord Chem Rev 252(10-11):1189-1199 
11. de Oliveira M, Gianeti TMR, da Rocha FCG, Lisboa-Filho PN, Piacenti-Silva M (2020) A preliminary study of the concentration of metallic elements in the blood of patients with multiple sclerosis as measured by ICP-MS. Sci Rep 10(1):1-8

12. De Riccardis L, Buccolieri A, Muci M, Pitotti E, De Robertis F, Trianni G, Manno D, Maffia M (2018) Copper and ceruloplasmin dyshomeostasis in serum and cerebrospinal fluid of multiple sclerosis subjects. Biochim Biophys Acta Mol basis Dis 1864(5 Pt A): $1828-1838$

13. Derkus B, Emregul E, Yucesan C, Emregul KC (2013) Myelin basic protein immunosensor for multiple sclerosis detection based upon label-free electrochemical impedance spectroscopy. Biosens Bioelectron 46:53-60

14. Dore-Duffy P, Catalanotto F, Donaldson JO, Ostrom KM, Testa MA (1983) Zinc in muliple sclerosis. Ann Neurol 14(4):450-454

15. Ellidag HY, Kurtulus F, Yaman A, Eren E, Yllmaz N, Aydin O, Bayındir A (2014) Serum iron metabolism markers including hepcidin in multiple sclerosis patients. Neurochem J 3(8):226-230

16. Erikson KM, Aschner M (2003) Manganese neurotoxicity and glutamate-GABA interaction. Neurochem Int 43(4-5):475-480

17. Erikson KM, Syversen T, Aschner JL, Aschner M (2005) Interactions between excessive manganese exposures and dietary iron-deficiency in neurodegeneration. Environ Toxicol Pharmacol 19(3):415-421

18. Filippi M, Preziosa P, Rocca MA (2016) Multiple sclerosis. Handb Clin Neurol 135:399-423

19. Foong J, Rozewicz L, Chong W, Thompson A, Miller D, Ron M (2000) A comparison of neuropsychological deficits in primary and secondary progressive multiple sclerosis. J Neurol 247(2):97-101

20. Forte G, Visconti A, Santucci S, Ghazaryan A, Figà-Talamanca L, Cannoni S, Bocca B, Pino A, Violante N, Alimonti A (2005) Quantification of chemical elements in blood of patients affected by multiple sclerosis. Ann Ist Super Sanita 41(2):213-216

21. Gelders G, Baekelandt V, Van der Perren A (2018) Linking neuroinflammation and neurodegeneration in Parkinson's disease. J Immunol Res 2018:1-12

22. Ghoreishi A, Mohseni M, Amraei R, Alizadeh A, Mazloomzadeh S (2015) Investigation the amount of copper, lead, zinc and cadmium levels in serum of Iranian multiple sclerosis patients. J Chem Pharm Sci 8:40-45

23. Haider L, Fischer MT, Frischer JM, Bauer J, Höftberger R, Botond G, Esterbauer H, Binder CJ, Witztum JL, Lassmann H (2011) Oxidative damage in multiple sclerosis lesions. Brain 134(Pt 7): 1914-1924

24. Ho SY, Catalanotto FA, Lisak RP, Dore-Duffy P (1986) Zinc in multiple sclerosis. II: Correlation with disease activity and elevated plasma membrane-bound zinc in erythrocytes from patients with multiple sclerosis. Ann Neurol 20(6):712-715

25. Horning KJ, Caito SW, Tipps KG, Bowman AB, Aschner M (2015) Manganese is essential for neuronal health. Annu Rev Nutr 35:71-108

26. Jensen GE, Gissel-Nielsen G, Clausen J (1980) Leucocyte glutathione peroxidase activity and selenium level in multiple sclerosis. J Neurol Sci 48(1):61-67

27. Johnson S (2000) The possible role of gradual accumulation of copper, cadmium, lead and iron and gradual depletion of zinc, magnesium, selenium, vitamins B2, B6, D, and E and essential fatty acids in multiple sclerosis. Med Hypotheses 55(3):239-241

28. Kapaki E, Segditsa J, Papageorgiou C (1989) Zinc, copper and magnesium concentration in serum and CSF of patients with neurological disorders. Acta Neurol Scand 79(5):373-378

29. Karpińska E, Socha K, Soroczyńska J, Kochanowicz J, Jakoniuk M, Mariak Z, Borawska MH (2017) Concentration of magnesium in the serum and the ability status of patients with relapsingremitting multiple sclerosis. J Elem 22(2):671-679
30. Kell DB (2009) Iron behaving badly: inappropriate iron chelation as a major contributor to the aetiology of vascular and other progressive inflammatory and degenerative diseases. BMC Med Genet 2(1): $1-79$

31. Kell DB (2010) Towards a unifying, systems biology understanding of large-scale cellular death and destruction caused by poorly liganded iron: Parkinson's, Huntington's, Alzheimer's, prions, bactericides, chemical toxicology and others as examples. Arch Toxicol 84(11):825-889

32. Kim Y-H, Jung K-I, Song C-H (2012) Effects of serum calcium and magnesium on heart rate variability in adult women. Biol Trace Elem Res 150(1-3):116-122

33. Korpela H, Kinnunen E, Juntunen J, Kumpulainen J, Koskenvuo M (1989) Serum selenium concentration, glutathione peroxidase activity and lipid peroxides in a co-twin control study on multiple sclerosis. J Neurol Sci 91(1-2):79-84

34. Kurup RK, Kurup PA (2002) Hypothalamic digoxin and hypomagnesemia in relation to the pathogenesis of multiple sclerosis. J Trace Elem Exp Med 15(4):211-220

35. LeVine SM, Chakrabarty A (2004) The role of iron in the pathogenesis of experimental allergic encephalomyelitis and multiple sclerosis. Ann N Y Acad Sci 1012(1):252-266

36. Masoud SA, Fakharian E (2007) Assessment of serum magnesium, copper, and zinc levels in multiple sclerosis (MS) patients

37. Matar A, Jennani S, Abdallah H, Mohsen N, Borjac J (2020) Serum iron and zinc levels in Lebanese multiple sclerosis patients. Acta Neurol Taiwanica 29(1):5-11

38. Mazzella G, Sinforiani E, Savoldi F, Allegrini M, Lanzola E, Scelsi R (1983) Blood cells glutathione peroxidase activity and selenium in multiple sclerosis. Eur Neurol 22(6):442-446

39. Mezzaroba L, Alfieri DF, Simão ANC, Reiche EMV (2019) The role of zinc, copper, manganese and iron in neurodegenerative diseases. Neurotoxicology 74:230-241

40. Mezzaroba L, Oliveira SR, Flauzino T, Alfieri DF, Pereira WLDCJ, Kallaur AP, Lozovoy MAB, Kaimen-Maciel DR, Maes M, Reiche EMV (2020) Antioxidant and anti-inflammatory diagnostic biomarkers in multiple sclerosis: a machine learning study. Mol Neurobiol:1-12

41. Mirshafiey A, Asghari B, Ghalamfarsa G, Jadidi-Niaragh F, Azizi $G$ (2014) The significance of matrix metalloproteinases in the immunopathogenesis and treatment of multiple sclerosis. Sultan Qaboos Univ Med J 14(1):e13

42. Olsson T, Barcellos LF, Alfredsson L (2017) Interactions between genetic, lifestyle and environmental risk factors for multiple sclerosis. Nat Rev Neurol 13(1):25-36

43. Oraby MI, Hussein M, Abd Elkareem R, Elfar E (2019) The emerging role of serum zinc in motor disability and radiological findings in patients with multiple sclerosis. Egypt J Neurol Psychiatr Neurosurg 55(1):1-5

44. Ortiz GG, Pacheco-Moisés FP, Bitzer-Quintero OK, RamírezAnguiano AC, Flores-Alvarado LJ, Ramírez-Ramírez V, MaciasIslas MA, Torres-Sánchez ED (2013) Immunology and oxidative stress in multiple sclerosis: clinical and basic approach. Clin Dev Immunol 2013:1-14

45. Pawlitzki M, Uebelhör J, Sweeney-Reed CM, Stephanik H, Hoffmann J, Lux A, Reinhold D (2018) Lower serum zinc levels in patients with multiple sclerosis compared to healthy controls. Nutrients 10(8):967

46. Polman, C., Reingold, S., Banwell, B., Clanet, M., Cohen, J., Filippi, M., Fujihara, K., Havrdova, E., Hutchinson, M., Kappos, L., 2011. O'Connor P., Sandberg-Wollheim M., Thompson AJ, Waubant E., Weinshenker B., Wolinsky. Diagnostic criteria for multiple sclerosis: 2010 revisions to the McDonald criteria. JS Ann Neurol 69, 292-302.

47. Popescu BF, Frischer JM, Webb SM, Tham M, Adiele RC, Robinson CA, Fitz-Gibbon PD, Weigand SD, Metz I, Nehzati S 
(2017) Pathogenic implications of distinct patterns of iron and zinc in chronic MS lesions. Acta Neuropathol 134(1):45-64

48. Poser CM, Paty DW, Scheinberg L, McDonald WI, Davis FA, Ebers GC, Johnson KP, Sibley WA, Silberberg DH, Tourtellotte WW (1983) New diagnostic criteria for multiple sclerosis: guidelines for research protocols. Ann Neurol 13(3):227-231

49. Ristori G, Brescianini S, Pino A, Visconti A, Vittori D, Coarelli G, Cotichini R, Bocca B, Forte G, Pozzilli C (2011) Serum elements and oxidative status in clinically isolated syndromes: imbalance and predictivity. Neurology 76(6):549-555

50. Sarmadi M, Bidel Z, Najafi F, Ramakrishnan R, Teymoori F, Zarmehri HA, Nazarzadeh M (2020) Copper concentration in multiple sclerosis: a systematic review and meta-analysis. Multiple Scler Relat Disord 45:102426

51. Schwarz S, Leweling H (2005) Multiple sclerosis and nutrition. Multiple Scler (Houndmills, Basingstoke, England) 11(1):24-32

52. Sedighi B, Ebrahimi HA, Haghdoost AA, Abotorabi M (2013) Comparison of serum levels of copper and zinc among multiple sclerosis patients and control group. Iran J Neurol 12(4):125-128

53. Sfagos C, Makis AC, Chaidos A, Hatzimichael EC, Dalamaga A, Kosma K, Bourantas KL (2005) Serum ferritin, transferrin and soluble transferrin receptor levels in multiple sclerosis patients. Mult Scler J 11(3):272-275

54. Sheykhansari S, Kozielski K, Bill J, Sitti M, Gemmati D, Zamboni P, Singh AV (2018) Redox metals homeostasis in multiple sclerosis and amyotrophic lateral sclerosis: a review. Cell Death Dis 9(3):116

55. Siotto M, Filippi MM, Simonelli I, Landi D, Ghazaryan A, Vollaro S, Ventriglia M, Pasqualetti P, Rongioletti MCA, Squitti R (2019) Oxidative stress related to iron metabolism in relapsing remitting multiple sclerosis patients with low disability. Front Neurosci 13:86

56. Sloot W, Korf J, Koster J, De Wit L, Gramsbergen J (1996) Manganese-induced hydroxyl radical formation in rat striatum is not attenuated by dopamine depletion or iron chelationin vivo. Exp Neurol 138(2):236-245
57. Smith DK, Feldman EB, Feldman D (1989) Trace element status in multiple sclerosis. Am J Clin Nutr 50(1):136-140

58. Socha K, Kochanowicz J, Karpińska E, Soroczyńska J, Jakoniuk M, Mariak Z, Borawska MH (2014) Dietary habits and selenium, glutathione peroxidase and total antioxidant status in the serum of patients with relapsing-remitting multiple sclerosis. Nutr J 13(1):62

59. Socha K, Karpińska E, Kochanowicz J, Soroczyńska J, Jakoniuk M, Wilkiel M, Mariak ZD, Borawska MH (2017) Dietary habits; concentration of copper, zinc, and $\mathrm{Cu}$-to- $\mathrm{Zn}$ ratio in serum and ability status of patients with relapsing-remitting multiple sclerosis. Nutrition 39:76-81

60. Vallee BL, Falchuk KH (1993) The biochemical basis of zinc physiology. Physiol Rev 73(1):79-118

61. Van Horssen J, Witte ME, Schreibelt G, de Vries HE (2011) Radical changes in multiple sclerosis pathogenesis. Biochim Biophys Acta (BBA) Mol Basis Dis 1812(2):141-150

62. Visconti A, Cotichini R, Cannoni S, Bocca B, Forte G, Ghazaryan A, Santucci S, D’Ippolito C, Stazi MA, Salvetti M (2005) Concentration of elements in serum of patients affected by multiple sclerosis with first demyelinating episode: a six-month longitudinal follow-up study. Ann Ist Super Sanita 41(2):217-222

63. Weiner HL (2004) Multiple sclerosis is an inflammatory T-cellmediated autoimmune disease. Arch Neurol 61(10):1613-1615

64. Yasui M, Ota K (1992) Experimental and clinical studies on dysregulation of magnesium metabolism and the aetiopathogenesis of multiple sclerosis. Magnes Res 5(4):295-302

65. Zecca L, Youdim MB, Riederer P, Connor JR, Crichton RR (2004) Iron, brain ageing and neurodegenerative disorders. Nat Rev Neurosci 5(11):863-873

Publisher's Note Springer Nature remains neutral with regard to jurisdictional claims in published maps and institutional affiliations. 